should be an island of poverty and misery in a sea of affluence and surfeit."

That Great Britain has a contribution to make at Government level to the assistance of developing countries is generally accepted. What the individual may do was discussed last year at the Annual Representative Meeting of the B.M.A. In a resolution it asked the Council to inquire into the desirability of setting up a system whereby retired but fit doctors might serve for a period in the developing countries which are short of medical manpower. This is certainly one possible source of medical men and women to draw upon, though the need to offer the right experience and qualifications must clearly be considered. As in Britain itself, some types of specialist posts abroad are more apt to be vacant than others; examples are to be found in radiology and pathology. Specialist posts of a permanent type in developing countries-say for two years or more-that are filled by doctors from Britain attract mainly men of registrar level and occasionally retired consultants. The other kind of permanent post, the general duty officer, usually has an upper age limit of 50 and exceptionally 55 . Vacancies in this category are much more difficult to fill than in special branches of medicine. The Ministry of Overseas Development recruits doctors on behalf of overseas Governments, and arrangements exist for supplementing from British funds the local salary paid to doctors working in underdeveloped countries. More young N.H.S. specialists would be encouraged to serve overseas for a few years if they could be certain their prospects of promotion in Britain would not be affected.

To the exhilaration of a new life that service in a developing country can bring may be added the interest of novel and abundant clinical problems. Moreover, the work is surely the more worth while if it helps to ease the tensions that lead to racial conflict, a pressing evil of our time.

1 Review of Second Decade of Public Health Work in Africa. Regional Office for Africa of the World Health Organization, 1968. Brazzaville, Republic of the Congo.

- Manuwa, Sir S., W. Afr. med. 7., 1967, 16, 169.

\section{Pituitary Ablation for Diabetic Retinopathy}

Destruction of the pituitary gland was introduced as a treatment for diabetic retinopathy by $R$. Luft and his colleagues. $^{1}$ The rationale of the treatment was J. E. Poulsen's ${ }^{2}$ description of a woman in whom diabetic retinopathy regressed when she developed post-partum pituitary necrosis. Though there are reports of over 400 patients treated in this way, opinions on its efficacy range from enthusiasm to reserve. Objective analysis is difficult owing to lack of truly comparable observations of treated and untreated patients.

The retinal lesions responsible for loss of vision in diabetes are new-vessel formation and fibrosis, retinal detachment, haemorrhages into the vitreous, and haemorrhages and exudates in the macular area. A useful indication of prognosis comes from a study ${ }^{3}$ of proliferative retinopathy in a group of patients with diabetes of juvenile onset who had no persistent proteinuria. One-fifth of the patients were blind in one eye when first seen. Half were blind in both eyes after five years' observation and half were dead in ten years. W. P. Beetham ${ }^{4}$ found that proliferating retinal lesions became completely quiescent before loss of vision had occurred in about $10 \%$ of untreated patients. He noted that the prognosis for retaining vision was worse in the elderly and that about two-thirds of young diabetics with retinopathy maintained good vision for an average of five years. In contrast, only a third of diabetics of maturity onset maintained good vision for an average of three and a half years. F. I. Caird and C. J. Garrett ${ }^{5}$ found that the rate of deterioration in vision increased with the severity of the lesions, so that $50 \%$ of eyes with initially impaired vision became blind in five years compared with $14.5 \%$ of eyes with good vision at first.

Only two reported studies have compared changes in visual acuity and retinal lesions in treated and untreated patients observed over the same period. G. F. Joplin and his colleagues $^{6}$ treated 19 patients by radioactive yttrium implant of the pituitary and found that visual acuity improved in $20 \%$ after a year but remained unchanged in 22 controls. New-vessel formation in the retina diminished in $30 \%$ of the treated patients and was unchanged in controls. Similar results were obtained by C. W. Rucker and his colleagues, ${ }^{7}$ who found that visual acuity deteriorated in only 9 of 33 patients treated by section of the pituitary stalk, whereas 19 out of 33 control patients showed change for the worse. Retinopathy improved in 16 of the treated patients compared with 9 of the control patients. R. F. Bradley and colleagues ${ }^{8}$ reviewed the results of treatment of 385 patients and noted that in these mostly uncontrolled studies stabilization or improvement in visual acuity and retinopathy occurred in about half the patients. Spontaneous improvement might have been expected in $10-30 \%$ of these, so there was a beneficial effect attributable to pituitary ablation in a minority of patients.

Though many different methods have been used to destroy the pituitary gland none has yet shown clear-cut superiority. Removal of the gland via a transfrontal or transethmoidal approach produces the most rapid loss of function, whereas section of the pituitary produces a more gradual and variable effect, as does destruction by proton beam irradiation, ${ }^{9}$ implants of seeds of radioactive yttrium and gold, or by stereotactic cryohypophysectomy. ${ }^{10}$ If pituitary function persists irradiation can be more readily repeated than can radical surgical procedures. There is evidence suggesting that the completeness of hypophysectomy is related to an effect on retinopathy, ${ }^{11}$ so that the more rapid and complete loss of pituitary function induced by surgical hypophysectomy may be an advantage for rapidly progressing retinopathy. All the procedures used to destroy the pituitary can cause transient or permanent cranial nerve palsies, and operations in which the skull is perforated are frequently complicated by cerebrospinal rhinorrhoea, less often by meningitis, and also by herpes simplex encephalitis. ${ }^{12}$ The incidence of these complications has now decreased ${ }^{13}$ but meningitis still causes one or two deaths in most series. In addition to the immediate operative risks patients are exposed to the hazards of life- 
long dependence on replacement therapy with steroids and possibly with thyroid and sex hormones as well.

It is not yet possible to predict which patients are going to retain vision as a result of pituitary ablation. The lesions most likely to be affected are microaneurysms, venous irregularities, new vessel formation, and retinal, preretinal, and vitreous haemorrhages. Proliferation of connective tissue usually continues though perhaps at a slower rate. Postoperative reduction of excessive retinal capillary permeability and opening up of areas of capillary closure has been shown by fluorescein angiography. ${ }^{14}$ These changes are frequently unaccompanied by improved vision, but useful vision may be retained. In addition to effects on the retinal circulation glomerular capillary abnormalities may regress $^{15}$ and proteinuria diminish, but despite this the renal blood flow and glomerular filtration rate fall even in those with initially good renal function. ${ }^{16}$ Neuropathy and arterial disease appear to be unaffected.

It is easier to define the contraindications for treatment than the indications. Ophthalmological contraindications include bilateral severe macular damage, retinal detachment, and preretinal lesions such as extensive fibrosis. Luft's ${ }^{1}$ early studies showed that pituitary ablation was poorly tolerated by the elderly and by those with heart disease, hypertension, neuropathy with postural hypotension, and severe renal disease. Many workers now also stipulate that patients treated should be less than 40 years old, should have at least two-thirds normal renal function, and should be free of chronic infection. Patients unlikely to cope with complex hormone replacement therapy should also be excluded. These restrictions eliminate three out of four potential subjects for pituitary ablation.

Most patients selected for treatment have relatively advanced retinopathy, with either useful vision lost in one eye or both eyes threatened by vascular lesions in the macula region. The results of treatment might be better if it was given at an earlier stage of the disease, but the potential morbidity and mortality of the procedure make it an unattractive proposition to someone with good vision in both eyes.

The available evidence suggests that pituitary ablation halts visual deterioration in from 20 to $40 \%$ of patients who would not have improved spontaneously. Many patients going blind will be prepared to chance the benefits and accept the risks, but they should be made aware of both.

1 Luft, R., Olivecrona, H., and Sjögren, B., f. clin. Endocr., 1955, 15, 391.

2 Poulsen, J. E., Diabetes, 1953, 2, 7.

Deckert, T., Simonsen, S. E., and Poulsen, J. E., Diabetes, 1967, 16, 728.

- Beetham, W. P., Brit. f. Ophthal., 1963, 47, 611.

5 Caird, F. I., and Garrett, C. J., Diabetes, 1963, 12, 389.

6 Joplin, G. F., Fraser, R., Hill, D. W., Oakley, N. W., Scott, D. J., and Doyle, F. H., Quart. F. Med., 1965, 34, 443.

Rucker, C. W., Gastineau, C. F., and Svien, H. J., Mayo Clin. Proc.,

1967, 42, 409. Bradley, R. F., Rees, S. B., and Fager, C. A., Med. clin. N. Amer., $1965,49,1105$

9 Lawrence, J. H., Tobias, C. A., Linfoot, J. A., Born, J. L., Gottschalk, A., and Kling, R. P., Diabetes, 1963, 12, 490.

Rand, R. W., Dashe, A. M., Paglia, D. E., Conway, L. W., and Solomon, D. H., f. Amer. med. Ass., 1964, 189, 255.

Joplin, G. F., Oakley, N. W., Hill, D.'W., Kohner, E. M., and Fraser, T. R., Diabetologia, 1967, 3, 406 .

12 Martins, A. N., Kempe, L. G., and Hayes, G. J., Milit. Med., 1966, 131,348 .

is Speakman, J. S., Mortimer, C. B., Briant, T. D. R., Ezrin, C., Lougheed, W. M., and Clarke, W. T. W., Canad. med. Ass. F., 1966, $94,627$.

14 Kohner, E. M., Dollery, C. T., Paterson, J. W., and Fraser, T. R., Excerpta med. (Amst.) International Congress Series No. 140, 1967, p. 13.

is Ireland, J. T., Patnaik, B. K., and Duncan, L. J. P., Diabetes, 1967,

16 Falkheden, T., Acta endocr. (Kbh.), 1963, 42, 571.

\section{Hyperventilation in Children}

Failure to recognize that hyperventilation in infants and children may be due to causes other than primary cardiorespiratory disease can have catastrophic consequences. The two most serious yet least frequently diagnosed causes are the states of overbreathing in salicylate poisoning and diabetic ketoacidosis. In both situations treatment may be urgently needed.

Hyperventilation may be the only clue to salicylate poisoning. Even on direct questioning parents occasionally deny having given aspirin or the possibility that the child has had access to it. Use of a Phenistix paper-strip test on the urine may be helpful. In this way $\mathrm{D}$. Pickering ${ }^{1}$ was able to establish the diagnosis of salicylate poisoning in spite of persistent denials from the parents. The pathogenesis of the overbreathing in salicylate poisoning is complex, and there are usually at least two phases in its causation. Initially it is due to direct stimulation of the respiratory centre by salicylate, and blood gas analysis at this time shows a respiratory alkalosis. The $\mathrm{PCO}_{2}$ is low and the $\mathrm{pH}$ rises. If the diagnosis is not made at this stage the patient gradually develops a state of metabolic acidosis owing to increasing dehydration from the hyperventilation and the accumulation of pyruvate and lactate, with the additional burden of ketonaemia as a result of inhibition of carbohydrate metabolism. In this phase of the illness there is a tendency to acidaemia, which in turn stimulates respiration, lowering the $\mathrm{PCO}_{2}$ further. The acidbase state of the patient cannot safely be assessed by the estimation of the plasma bicarbonate alone, as it will be reduced in both phases of the illness.

Hyperventilation in diabetic ketoacidosis of childhood is usually accompanied by marked disturbances in hydration, and the patient may rapidly become moribund. Overbreathing in this situation is the end result of acidaemia and of the effort to correct this by blowing off $\mathrm{CO}_{2}$ derived from carbonic acid in the blood. The onset of diabetes mellitus in childhood may be alarmingly acute. Overbreathing is a constant finding in diabetic acidosis, but the diagnosis may be obscured by the presence of abdominal rigidity or neck stiffness. Examination of the urine for sugar and ketones is essential.

There are other important causes of overventilation. In infants metabolic acidosis may develop rapidly after apparently trivial vomiting and diarrhoea. In a plump baby dehydration may be difficult to assess; he may overbreathe, and a common mistake then is to diagnose a respiratory infection. Valuable time may be lost in relying on antibiotics, whereas fluid replacement is the appropriate treatment. Hyperventilation may develop in encephalitis as a result of stimulation of the respiratory centre. There may be signs of meningeal irritation and clouding of consciousness. Hysterical overbreathing is rare in very young children but may occur in older ones. The overventilation occurs mainly in attacks, and often leads to tetany. Sulthiame (Ospolot), commonly used in the treatment of grand mal epilepsy, may occasionally be responsible for hyperventilation.

Both salicylate poisoning and diabetic ketoacidosis can be managed only in hospitals in which facilities are available for serial biochemical assessment of the patient's response to therapy. Early diagnosis improves the prognosis immeasurably. Even if there are definite signs of respiratory disease the general practitioner should be cautious about diagnosing

\footnotetext{
1 Pickering, D., Acta paediat. (Uppsala), 1964, 53, 501.
} 